\title{
СИНТЕЗ ЧЕТВЕРТИЧНЫХ АММОНИЕВЫХ СОЛЕЙ НА ОСНОВЕ ПРОДУКТОВ ТЕЛОМЕРИЗАЦИИ ДИЕНОВЫХ УГЛЕВОДОРОДОВ
}

К настоящему времени разработано довольно много методов синтеза ч: твертичных аммониевых солей (ЧАС). Однако в основу промышленных процессов положены только те из них, которые позволяют получать продукты с требуемыми свойствами, использовать доступное сырье и являются экономически эффективными $\left[{ }^{1-4}\right]$.

ЧАС с углеводородным радикалом, содержащим 12-18 углеродных атомов, обладают поверхностной активностью. Такие катионные поверхностно-активные вещества (ПАВ) впервые были использованы как бактерицидные препараты. В настоящее время они применяются в качестве флотореагентов, эффективных экстрагентов в цветной металлургии. На их основе изготавливаются текстильно-вспомогательные вещества, дезинфицирующие, моющие, гербицидные и другие препараты.

В основу процессов получения ЧАС положены следующие реакции:

$$
\mathrm{R}-\mathrm{NH}_{2}+3 \mathrm{R}^{\prime} X+2 \mathrm{NaOH} \rightarrow\left[\mathrm{R}-\mathrm{N}\left(\mathrm{R}^{\prime}\right)_{3}\right]+X-+2 \mathrm{Na} X+2 \mathrm{H}_{2} \mathrm{O},
$$

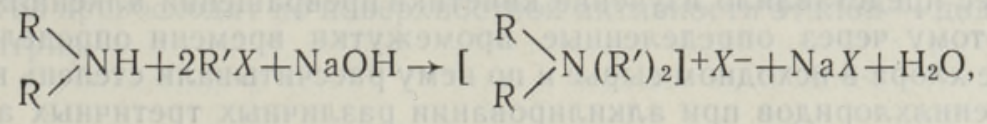

$$
\begin{gathered}
\mathrm{N}\left(\mathrm{CH}_{3}\right)_{3}+\mathrm{RX} \rightarrow\left[\mathrm{R}-\mathrm{N}\left(\mathrm{CH}_{3}\right)_{3}\right]^{+} X^{-}, \\
\mathrm{R}-\mathrm{N}\left(\mathrm{CH}_{3}\right)_{2}+\mathrm{R}^{\prime} X \rightarrow\left[\mathrm{RR}^{\prime} \mathrm{N}\left(\mathrm{CH}_{3}\right)_{2}\right]^{+} X^{-},
\end{gathered}
$$

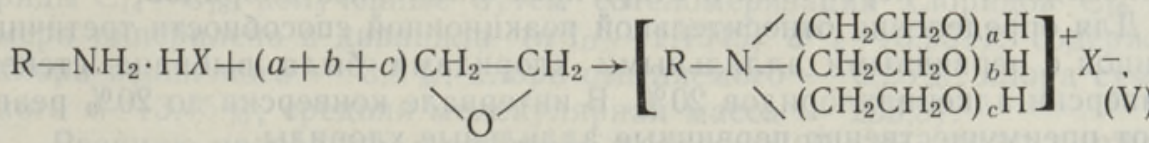

$$
\begin{aligned}
& \mathrm{R}-\mathrm{N}\left(\mathrm{CH}_{3}\right)_{2}+\left(\mathrm{CH}_{3}\right)_{2} \mathrm{SO}_{4} \rightarrow\left[\mathrm{R}-\mathrm{N}\left(\mathrm{CH}_{3}\right)_{3}\right]+\mathrm{SO}_{4} \mathrm{CH}_{3}^{-} \text {, } \\
& \mathrm{R}-\mathrm{OCH}_{2} \mathrm{~N}\left(\mathrm{C}_{2} \mathrm{H}_{5}\right)_{2}+\mathrm{R}^{\prime} X \rightarrow\left[\mathrm{ROCH}_{2} \mathrm{~N}\left(\mathrm{C}_{2} \mathrm{H}_{5}\right)_{2} \mathrm{R}^{\prime}\right]+X^{-} \text {. }
\end{aligned}
$$

Наиболее просто протекает процесс получения ЧАС по двум первым реакциям. В этом случае первичные или вторичные алкиламины реагируют с галоидалкилами $\mathrm{C}_{1}-\mathrm{C}_{4}$ (чаще с хлористым метилом) в среде растворителя при температуре $50-100^{\circ} \mathrm{C}$ и атмосферном давлении или под небольшим давлением [5-7]. Скорость реакции между аминами и алкилирующими агентами в значительной степени зависит от типа растворителя, состава и строения реагирующих компонентов.

В промышленных масштабах источниками сырья для получения ЧАС служат хлористый метил, хлористый бензил, диметилсульфат, алкилхлориды $\mathrm{C}_{10}-\mathrm{C}_{18}$, алкилбензилгалоиды $\left[{ }^{8,9}\right]$. Нами для этих целей выбран пиперилен - диеновый углеводород, содержащий пять атомов углерода в молекуле.

Наращивание углеводородной цепи осуществляли путем теломеризации пиперилена с его гидрохлоридом в присутствии катализатора (IV) хлорида олова: 


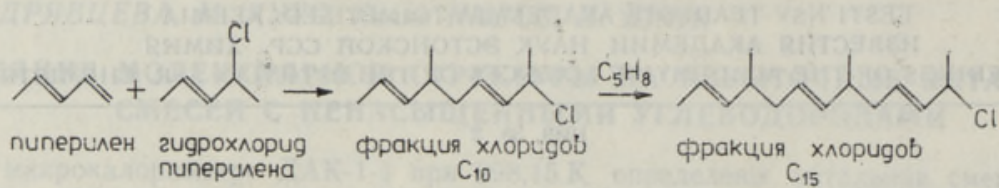

Таким образом получали алкенилхлориды $\mathrm{C}_{10}, \mathrm{C}_{15}$ и некоторое количество $\mathrm{C}_{20}$. Фракция $\mathrm{C}_{15}$ может использоваться для получения алкенилсульфонатов, нами получен выход $50-52 \%$ [10]. Фракция же $\mathrm{C}_{10}$ не пригодна для этой цели. Поэтому после отгонки $\mathrm{C}_{10}$ из реакционной смеси ее подвергали утилизации путем повторной сотеломеризации с дивинилом в присутствии (IV)хлорида олова:

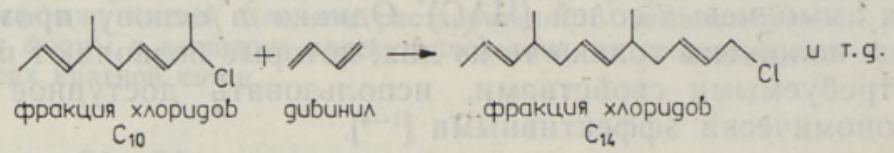

Таким образом получали алкенйлхлориды $\mathrm{C}_{14}, \mathrm{C}_{18}$ и выше. Такие соединения, имеющие первичный атом хлора в 1-м положении по отношению к двойной связи, являются перспективными алкилирующими агентами для получения ЧАС.

Нами была изучена возможность алкилирования алкенилхлоридами следующих доступных третичных аминов: диметиланилина, пиридина и триэтаноламина. В целях установления влияния структуры третичного амина на реакцию алкилирования процесс проводили в равных условиях: в растворе изопропилового спирта при нормальном давлении. При этом интерес представляло изучение кинетики превращения алкенилхлоридов. Поэтому через определенные промежутки времени определяли содержание хлора в исходном сырье и по нему рассчитывали степень конверсии алкенилхлоридов при алкилировании различных третичных аминов.

Кинетические кривые реакции алкенилхлоридов с третичными аминами (рисунок) указывают на участие в процессе двух видов галогенопроизводных - первичных и вторичных аллильных хлоридов.

Для определения относительной реакционной способности третичных аминов с первичными аллильными хлоридами была выбрана степень конверсии алкенилхлоридов $20 \%$. В интервале конверсии до $20 \%$ реагируют преимущественно первичные аллильные хлориды.

Данные на рисунке показывают, что в выбранных условиях проведения реакции относительная реакционная способность третичных аминов с первичными аллильными хлоридами составляет соответственно пиридин : триэтаноламин : диметиланилин $3,6: 1,4: 1$.

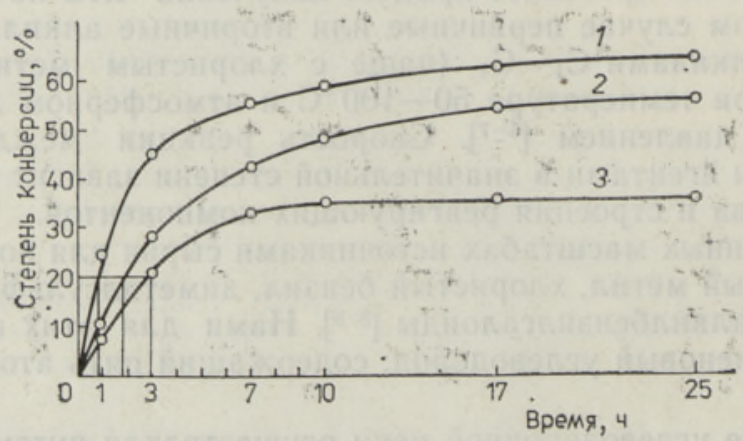

Кинетические кривые реакции алкилироваңия пиридина (1), триэтаноламина (2), диметиланилина (3). 


\begin{tabular}{|c|c|c|c|c|c|}
\hline \multirow{2}{*}{ ПАВ } & \multirow{2}{*}{ Формула } & \multicolumn{4}{|c|}{$\begin{array}{c}\text { Поверхностное натяжение, } 10-5 \cdot \mathrm{H} / \mathrm{cm} \text {, } \\
\text { водных растворов, мас. } \%\end{array}$} \\
\hline & & 0,5 & 0,25 & 0,125 & 0,063 \\
\hline $\begin{array}{l}\text { Додецилсульфат } \\
\text { натрия (эталон) }\end{array}$ & $\mathrm{CH}_{3}-\left(\mathrm{CH}_{2}\right)_{10}-\mathrm{C}$ & 39,2 & 39,3 & 41,3 & 52,8 \\
\hline $\begin{array}{l}\text { Хлорид } \\
\text { алкенилпирндиния }\end{array}$ & & 30,0 & 34,5 & 36,6 & 39,5 \\
\hline $\begin{array}{l}\text { Хлорид алкснил- } \\
\text { диметилпиридиния }\end{array}$ & & 21,2 & 31,1 & 31,5 & 32,3 \\
\hline $\begin{array}{l}\text { Хлорнд алкенил- } \\
\text { триэтаноламмония }\end{array}$ & & 30,7 & 31,0 & 32,3 & 33,0 \\
\hline
\end{tabular}

Спиртовой раствор ЧАС после отделения от остаточных хлоридов промывали петролейным эфиром и упаривали в вакууме. Остаток экстрагировали этанолом и высушивали при $30-40^{\circ} \mathrm{C}$.

Статическое поверхностное натяжение водных растворов различной концентрации определяли сталагмометрическим методом [1'] при $20^{\circ} \mathrm{C}$. Полученные данные (таблица) показывают, что все синтезированные ЧАС превосходят по поверхностной активности эталон - додецилсульфат натрия.

\section{Экспериментальная часть}

Исходным сырьем для синтеза ЧАС служили соответствующие хлориды $\mathrm{C}_{14}-\mathrm{C}_{18}$, полученные путем сотеломеризации хлоридов $\mathrm{C}_{10}$ теломера пиперилена и дивинила $\left(n^{20}{ }_{D}-1,4949 ; d^{20}{ }_{4}-0,9511 ;\right.$ содержание хлора первичного - $3,5 \%$; хлора омыляемого - $8,25 \%$; хлора суммарного - $13,45 \%$; средняя молекулярная масса - 253,5).

Реакцию проводили в среднем в течение 25 ч при $50{ }^{\circ} \mathrm{C}$ с $10 \%$-ным избытком амина от стехиометрически необходимого количества, рассчитанного по содержанию общего хлора в алкенилхлоридах. Растворителем служил изопропиловый спирт, взятый по массе в отношении к амину $1: 1$. В реактор, снабженный мешалкой, термометром и обратным холодильником, последовательно загружали взвешенные количества алкенилхлоридов $\mathrm{C}_{14}-\mathrm{C}_{18}$, изопропилового спирта и амина. Критерием протекания реакции служит величина омыляемого хлора в остаточных хлоридах, которая по мере протекания реакции должна уменьшаться. Реакция ведется до тех пор, пока величина омыляемого хлора не достигает постоянного минимума. По окончании реакции смесь обрабатывали $50 \%$-ным водным раствором изопропилового спирта и петролейным эфиром (темп. кип. $40-70^{\circ} \mathrm{C}$ ) из расчета 200 г водного спирта и 50 г петролейного эфира на 100 г загружаемых алкенилхлоридов. Смесь перемешивали в течение 10 мин. После отстоя образуется два слоя: петролейный эфир и водный 2-пропанол. Слои разделяли, и экстракцию повторяли по схеме т.н. псевдопротивотока (3 раза). Соответствующие слои объединяли, петролейный эфир отгоняли. Остаток дистилляции представлял собой непрореагировавшие алкенилхлориды, в которых определяли хлор омыляемый. 
Из суммарного водно-спиртового слоя отгоняли изопропиловый спирт и воду при разрежении водоструйного насоса. К остатку дистилляции добавляли воду, и вновь перегоняли в целях удаления следов аминов в виде азеотропа с водой, обладающих резким специфическим запахом. Отгонку воды вели до начала интенсивного пенообразования, после чего концентрат упаривали на водяной бане. В остатке остается соль четвертичного полиалкениламмониевого основания, в которой определяли содержание ионного хлора.

1. Реакция с пиридином. Брали 100,3 г исходных алкенилхлоридов, 20,2 г пирндина, 50,0 г 2-пропанола. Получали 84,3 г продукта (выход $100 \%$ от реакционноспособных хлоридов) и 36,0 г остаточных хлоридов. В продукте определяли хлор ионный, который составлял 9,9\%, что соответствует содержанию ЧАС в количестве $92,3 \%$.

2. Реакция с диметиланилином. Брали 100,1 г исходных алкенилхлоридов, 30,9 г диметиланилина, 50,0 г 2-пропанола. Получали 52,0 г продукта (выход 53,6\% от реакционноспособных хлоридов) и 64,0 г остаточных хлоридов. В продукте определяли хлор ионный, который составлял $8,5 \%$, что соответствует содержанию ЧАС в количестве $89,5 \%$.

3. Реакция с триэтаноламином. Брали 100,0 г исходных алкенилхлоридов, 38,0 г триэтаноламина, 50,0 г 2-пропанола. Получали 88,7 r продукта (выход $82,7 \%$ от реакционноспособных хлоридов) и 44,0 г остаточных хлоридов. В продукте определяли хлор ионный, который составлял $7,7 \%$, что соответствует содержанию ЧАС в количестве $87,7 \%$.

Большинство ЧАС хорошо растворимы в низших спиртах, хлоралканах, ацетоне и практически нерастворимы в серном и петролейном эфире. В воде хорошо растворяются ЧАС, содержащие один длинный углеводородный радикал и три коротких, к которым можно отнести и синтезированные нами соединения. Использованию ЧАС в ряде процессов препятствует их невысокая термическая стабильность (разложение начинается выше $100{ }^{\circ} \mathrm{C}$ ). Это необходимо учитывать при их сушке в конечной стадии получения ЧАС.

\section{Выводы}

1. Разработан способ получения катионных поверхностно-активных веществ - четвертичных аммониевых солей на основе продуктов сотеломеризации пиперилена и дивинила.

2. Реакция осуществлялась между алкенилхлоридами $\mathrm{C}_{14}-\mathrm{C}_{18}$ и третичными аминами - пиридином, диметиланилином, триэтаноламином при атмосферном давлении в присутствии безводного 2-пропанола в течение 25 ч при температуре $50^{\circ} \mathrm{C}$. Выход продукта составляет в среднем соответственно 100, 53 и $82 \%$.

3. Кинетические кривые алкилированных третичных аминов свидетельствуют о протекании двух реакций с первичными и вторичными аллильными хлоридами.

4. При выбранных условиях алкилирования первичными аллильными хлоридами относительная реакционная способность третичных аминов составляет соответственно пиридин:триэтаноламин:диметиланилин $3,6: 1,4: 1$.

5. Синтезированные четвертичные аммониевые соли $\mathrm{C}_{14}-\mathrm{C}_{18}$ обладают хорошими поверхностно-активными свойствами. 
1. Гериенович A. И., Стефанович В. В. Получение и применение катионных поверхностно-активных веществ на основе алкилбензолов // Хим. пром-сть, 1964, № 6, $16-18$.

2. Волынский Н. П., Смолянинов В. В. Образование тетра- и пентатионатов при действии кислот на тиосульфаты в присутствин солей некоторых органических оснований // Ж. орг. хим., 1963, 33, № 5, 1461-1463.

3. Комков И. П., Ворона Н. И. Поверхностно-активные четвертичные аммониевые соли $o$-ацилхолинов // Изв. ВУЗов. Хнмия и хим. технол., 1971, 14, 1369-1373.

4. Egan, R. R. Cationic surface active agents as fabric softeners // J. Amer. Oil Chem. Soc., $1978,55,118-121$.

5. Лиманов В. Е., Нванов С. Б., Крученок Т. Б., Цвирова И. М. Синтез и бактерицидная активность катионных поверхностно-активных веществ, содержащих асимметричный атом азота // Хим.-фарм. ж., 1984, 18, № 6, 703-706.

6. Борисова H. Н., Лиманов В. Е., Старков А. В. Способ получення четвертичных аммониевых соединений с помощью циркуляционной установки // Ж. прикл. хим., 1968, № 6, 1362-1364.

7. Tamamushi, B., Watanabe, N. $\beta$-Hydroxydodecyldimethylbenzylammonium chloride as a new cationic surfactant // Tenside, 1980, 17, N 4, 193-196.

8. Schwitzer, M. K. Fats as a source for cationic surfactants // Chem. Ind., 1979, 6, N $1,11-15$.

9. Gawish, S. M., Hazzaa, A. A. D., El-Din Gebril, B. Cationic surface-active agents // J. Amer. Oil Chem. Soc., 1978, 55, 745-747.

10. Лиив T., Кудрявцев Н., Когерман А., Лээтс К. Синтез алкенилсульфонатов на основе продуктов теломеризации пиперилена // Изв. АН ЭССР. Хим., 1987, 36, № 3, $195-199$.

11. Абрамзон А. А. Поверхностно-активные вещества, свойства и применение. Л., 1975, 50.

\section{Ннститут химии Поступила в редакцию Академии наук Эстонской ССР $19 / \mathrm{X} 1988$}

Tatjana LIIV, I. KUDRJAVTSEV, A. KOGERMAN, K. LÄATS

\section{KVATERNAARSETE AMMOONIUMISOOLADE SUNTEES DIEENSETE SUSIVESINIKE TELOMERISATSIOONIPRODUKTIDE BAASIL}

On esitatud meetod katioonsete pindaktiivsete ainete saamiseks. Need kujutavad endast piperüleeni ja divinüüli telomerisatsiooni produktide kvaternaarset ammooniumisoola. Reaktsioon kulgeb alkenüülkloriidide $\mathrm{C}_{14}-\mathrm{C}_{18}$ ja tertsiaarsete amiinide, nagu püridiini, dimetüülaniliini või trietanoolamiini vahel isopropanooli manulusel temperatuuril $50^{\circ} \mathrm{C}$ normaalrõhul. Saaduseks on heade omadustega pindaktiivsed ained.

\section{Tatyana LITV, I. KUDRYAVTSEV, A. KOGERMAN, K. LÄATS}

\section{SYNTHESIS OF QUATERNARY AMMONIUM SALTS ON THE BASIS OF TELOMERIZATION PRODUCTS OF DIENIC HYDROCARBONS}

The paper reports a method of obtaining cationic surfactants - quaternary ammonium salts on the basis of telomerization products of piperylene and divinyl. The reaction between alkenyl chlorides $\mathrm{C}_{14}-\mathrm{C}_{18}$ and tertiary amines, viz. pyridine, dimethyianiline, triethanolamine, is carried out in the presence of isopropanol at $50^{\circ} \mathrm{C}$ at normal pressure. The products obtained have good surface-active properties. 